\title{
КОММУНИКАТИВНЫЕ СТРАТЕГИИ КОНСТРУИРОВАНИЯ КОНЦЕПТА «ПОЛИТИЧЕСКОЕ БЛАГОПОЛУЧИЕ»
}

\author{
Лукьянова Наталия Александровна 1,2 , \\ lukianova@tpu.ru \\ Рвалов Павел Николаевич 1 , \\ rvalov@tpu.ru \\ 1 Томский политехнический университет, \\ Россия, 634050, г. Томск, пр. Ленина, 30
}

\begin{abstract}
2 Новгородский государственный университет имени Ярослава Мудрого, Россия, 173003, Великий Новгород, ул. Большая Санкт-Петербургская, 41
\end{abstract}

Лукьянова Наталия Александровна, доктор философских наук, руководитель отделения социально-гуманитарных наук Томского политехнического университета; профессор кафедры философии, культурологии и социологии Новгородского государственного университета имени Ярослава Мудрого.

Рвалов Павел Николаевич, кандидат философских наук, начальник управления молодежной и социальной политики Томского политехнического университета Россия.

\begin{abstract}
Актуальность. Установление закономерностей конструирования концепта «политическое благополучие» в плотной сети коммуникаций современной культуры является научной проблемой и позволяет сформировать новое междисциплинарное предметное поле в современных философскокультурологических исследованиях. Цель: выявить коммуникативные стратегии конструирования концепта «политическое благополучие», обусловленные закономерностями протекания процессов стереотипизации в социокультурных коммуникациях и особенностями познаваемости мира посредством его конструирования. В статье использован ряд методов, позволяющих осуществить философский и социально-психологический анализ сущности и взаимообусловленности концептов «благополучие» и «политика». На основе теории общественного мнения У. Липпмана исследуется роль стереотипов в конструировании концепта «политическое благополучие». Результаты: политическое благополучие рассматривается как переживание совокупности объективных обстоятельств, обусловленных системой властных отношений и институтов власти во взаимосвязи с субъективным состоянием. Конструирование концепта «политическое благополучие» напрямую связано с коммуникативными процессами как способами говорения о мире политики, которые характерны для различных социальных групп и влекут за собой различные социальные действия. В процессе конструирования ключевыми становятся две коммуникативные стратегии: в рамках первой формируется «образ для себя» - понимание политического благополучия как собственного блага, которое складывается из комплекса личных традиционных благ. Вторая коммуникативная стратегия - это «образ для других» (политико-культурные и иные реальности, обычаи, национальные мифы, символы, верования, стереотипы). В основе данной стратегии лежат механизмы формирования общественного мнения, особо подчеркивается значение процессов социальной стереотипизации. Выводы: конструирование конщепта «политическое благополучие» осуществляется посредством двух коммуникативных стратегий. Парадоксальность ситуации в том, что концепт «политическое благополучие» в формате «образ для себя» в представлениях граждан строится на стереотипах формата «образ для других».
\end{abstract}

Ключевые слова: Коммуникации, политическое благополучие, конструирование, концепт, стереотип, политика, манипулирование, теория общественного мнения. 


\section{Политическое благополучие: к определению понятия}

В современной нам реальности исследование концепта благополучия в его многообразных проявлениях становится важным условием понимания текущих изменений и прогнозирования будущего. Представление о счастье и благополучии присутствует в философии, религии, а также в исследованиях психологов и культурологов. При этом необходимо отметить многообразие терминов, характеризующих собственно концепт «благополучие». Говоря о концепте в данном исследовании, мы будем придерживаться определения, данного С.С. Неретиной: «Концепт, в отличие от формы «схватывания» в понятии (intellectus), которое связано с формами рассудка, есть производное возвышенного духа (ума), который способен творчески воспроизводить или собирать (concipere) смыслы и помыслы как универсальное, представляющее собой связь вещей и речей, и который включает в себя рассудок как свою часть» [1]. И далее - из другого источника: «Концепт завершает концептуализацию и зачинает новое движение в усилиях человека по рационально-эмоциональному постижению мира вообще и политики в частности» [2, с. 7].

Рассматривая проблемы политического благополучия, необходимо помнить, что как таковое благополучие связывается с многообразием субъективных и объективных оценок в экономике, здоровье, качестве жизни и пр. По мнению D.M. Smith [3], термин «благополучие» должен использоваться исключительно по отношению к объективным показателям условий жизни населения, тогда как «качество жизни» - по отношению к субъективной оценке людей их жизни. Противоположная точка зрения (B.K. Нaas $[4$, p. 4]) рассматривает благополучие как одну из компонент качества жизни, которая имеет отношение к субъективной оценке людей их собственной жизни.

Кроме того, анализируя концепт «политическое благополучие», необходимо понимать, что речь идет в первую очередь о социально-экономической стабильности в силу того, что стабильность политической сферы зависит от многих таких факторов, как: параметры социально-экономического развития, социальные индикаторы, продуктивность антикоррупционных мер, эффективность конституционного строя. Это и многое другое определяют результативность политики государства. В этой части благополучие будет ближе не к понятию счастья, как его описывал Н. Карамзин. Напомним, что в его «Диалоге о счастии» Мелодор и Филалет рассуждают на тему счастья и благополучия. Счастье представляется в виде божества, к которому каждый протягивает руки. ...Счастье и благополучие должны быть общим добром человечества, т. к. природа создала человеку все условия для создания семьи, обустройства дома и любви [5]. Политическое благополучие более определяется с позиции аристотелевского понимания блага. Совершая поступки, делая сознательный выбор, увлекаясь искусством, мы стремимся к благу. В «Никомаховой этике» под благоденствием и благополучием подразумевается счастливая жизнь. Для людей счастье наглядно и очевидно, у разных людей разное счастье - «заболев, люди видят счастье в здоровье, впав в нужду - в богатстве» [6]. Благо не может быть всеобъемлюще общим и единым. Для больного благо выздоровление, для военачальника - победа, для неимущего - богатство. Правильный поступок есть путь к благу. «Подобно тому, как на олимпийских состязаниях венки получают не самые красивые и сильные, а те, кто участвовал в состязании, так в жизни, прекрасного и благого достигают те, кто совершает правильные поступки» [6, с. 67]. Одновременно Аристотель дал понимание того, что способность властвовать и подчиняться не относятся к добродетелям гражданина. Поэтому вопрос о политическом благополучии как таковом им не ставится. В аристотелевской «Политике» речь идет о политии как форме общения свободных людей. Таких людей Аристотель называет «государственными общинниками», т. е. имеющими отношение к общему благу...» [2, с. 39]. 
Итак, благо в контексте политии можно рассматривать как череду правильных поступков. Одновременно важно понимать дискурсивную природу концепта «благополучие».

Например, в работе «Государство» Платон рассуждает об идее блага как удовольствии. Благо Платона не всеобъемлюще, оно носит субъективный характер и каждый пытается обрести подлинное благо. «Познаваемые вещи могут познаваться благодаря благу; оно же дает им и бытие, и существование, хотя само благо не есть существование, оно - за пределами существования, превышая его достоинством и силой» [7]. На это важно обратить внимание, поскольку здесь мы акцентируем внимание на двух направлениях в исследовании благополучия как такового: индивидуалистическом и универсалистском. Как отмечал позднее В. Виндельбанд, «интерес образованного человека эпохи Просвещения сосредоточен либо на проблемах жизни отдельного человека, либо на идеальных задачах человеческого рода» [8, с. 299].

И в этом случае концепт «политическое благополучие» конструируется, с одной стороны, как благо общественное, где счастье и благополучие достигаются взаимными усилиями. Благополучие одних людей зависит от счастья и блага других. Человек будет считаться добродетельным в случае (по словам Д. Дидро), если все его стремления и «аффекты» идут на общее благо его рода, частью которого он является. С другой стороны, как у Г. Гегеля, человек есть всегда в его противопоставлении «существа единичного» «существу общественному». «Ощущение блага как соответствие внешнего нашему внутреннему мы называем также удовольствие. Благоденствие представляет собой не единичное удовольствие, а продолжительное состояние отчасти самого действительного удовольствия» [9, с. 34]. И тогда мы говорим об индивидуальном благополучии. В этом случае политическое благополучие есть «пучок» представлений, понятий, знаний, ассоциаций, переживаний, который сопровождает слово политика. И этот концепт существует в сознании (в ментальном мире) человека (не специализирующимся на политике), не в виде четких понятий об особенностях политического устройства, смены власти и пр., а как переживание (поскольку концепты не мыслятся, а переживаются, по мнению Ю.С. Степанова) совокупности объективных обстоятельств, обусловленных системой властных отношений и институтов власти во взаимосвязи с субъективным удовлетворением. И в этом случае мы можем говорить о коммуникативных стратегиях конструирования концепта «политическое благополучие». Мы говорим именно о конструировании посредством коммуникаций, поскольку это есть способ говорения о мире (политике), характерный для различных социальных групп и влекущий за собой различные социальные действия.

Рассмотрим данный тезис подробнее. Концепт «политическое благополучие» включает идеи общего блага, описанные философами, античности, просвещения, нового времени. Не существует описания собственно этого концепта, однако практически во всех описаниях концептов «благополучия» или «блага» присутствуют взаимовключение и взаимопересечение объективного и субъективного. Современные исследователи Д. Парфит, Д. Гриффин, М. Нуссбаум разработали теорию объективного списка (object list theory). Она основана на том, что к благополучию приводит совокупность объективных обстоятельств, а не субъективное удовольствие или исполнение личных желаний. Согласно этой теории, существуют блага, которые способствуют нашему благополучию, даже если мы не желаем их или не испытываем удовольствие от них. Человек достигает благополучия только в том случае, если в его жизни есть все или большая часть благ из списка. Приобретая блага из списка, человек улучшает свою жизнь, даже если он этого не желает. Например, Дерек Парфит предложил список, который включает в себя как великодушие и благородство, так и рациональную деятельность, развитие 
способностей, детей, необходимость быть хорошими родителями, знание и пониманием истинной красоты [10]. Список Джеймса Гриффина включает достижения, компоненты человеческого существования (автономия, способности, свобода), понимание, удовольствие и глубокие личные отношения [11]. Как мы видим, все эти пункты списков есть отражение различных видов взаимодействия людей.

\section{Две стратегии конструирования конструкта «политическое благополучие»}

Говоря о политическом благополучии, необходимо отметить, что для человека как существа социального и его политическое благополучие связано с благополучием социума. В этом случае можем говорить, что существует две коммуникативные стратегии конструирования концепта «политическое благополучие» в современном социуме. Коммуникация понимается как процесс совместного создания сообщений и одновременно выражения идей и чувств. В рамках первой коммуникативной стратегии формируется «образ для себя». И в этом случае «образ для себя» представляет собой понимание политического благополучия как бы изнутри, которое складывается из комплекса личных традиционных благ: физическое и психическое здоровье, материальные и нематериальные блага. По сути, есть списки компонентов человеческого существования (см. выше список Гриффина и Парфита).

Вторая коммуникативная стратегия - это «образ для других» - политикокультурные и иные реальности, обычаи, национальные мифы, символы, верования, стереотипы и т. д. И в этом случае важен внешний адресат. Как правило, политическое благополучие в большей степени становится образом для других [12, с. 123]. Представляется, что в основе концепта «политическое благополучие» как образа для других лежит идея общественного мнения. Существует комплекс представлений о внешнем миpe, который имеет отношение к мнению окружающих людей в той степени, в которой это мнение связано с мнением индивида и зависит от него (за основу мы берем теорию общественного мнения У. Липпмана [13]). Сам Липпман так описал стереотип: «характерное явление обыденного сознания, основанное на стремлении человека свести разнообразие мира к немногим определенным категориям и тем самым облегчить себе восприятие, понимание и оценку явлений» [13, с. 96]. Таким образом, можно утверждать, что представление о политическом благополучии в формате «образ для других» формируется через общественное мнение.

Согласно У. Липпману, подчиняясь разнообразию мира, человек систематизирует знание о нём в категориях. Эти категории есть образы, воплощенные в разнообразных знаках и символах, с помощью которых человек приспосабливается к своему окружению. Это могут быть фикции, стереотипы, элементы псевдосреды и пр. С этой идеей созвучно представление об общественном мнении Элизабет Ноэль-Нойман - автора гипотезы «спирали молчания», специалиста в области общественного мнения. «Общественное мнение - это ценностно окрашенное, в частности имеющее моральную окраску, мнение и способ поведения, которые, если речь идёт об устоявшемся, закрепившемся согласии, например догме или обычае, следует демонстрировать прилюдно, если не хочешь оказаться в изоляции, или которые в проходящих состояниях можно прилюдно демонстрировать, не боясь изоляции» [14]. Итак, говоря о политическом благополучии как результате конструирования «образа для других», мы будем рассматривать его в первую очередь как переживание связанности идей общественного мнения с собственными (субъективными) представлениями. Уверенность в том, что будет возможность строить свое собственное (личное) будущее, - это и есть ключевая составляю- 
щая политического благополучия. Это есть доверие к власти и ощущение защищенности.

\section{О роли социальных стереотипов в конструировании концепта «политическое благополучие»}

В философском дискурсе присутствует следующее определение стереотипа: «стереотип социальный (от греч. stereos - твердый, typos - отпечаток) - устойчивая совокупность представлений, складывающихся в сознании как на основе личного жизненного опыта, так и с помощью многообразных источников информации. Сквозь призму социальных стереотипов воспринимаются реальные предметы, отношения, события, действующие лица. Социальные стереотипы - это неотъемлемые компоненты индивидуального и массового сознания. Благодаря социальным стереотипам происходит необходимое сокращение восприятия и иных информационных и идеологических процессов в сознании, закрепляется как положительный, так и отрицательный опыт людей...» [15].

По мнению Липпмана, человек выбирает те признаки мира, соответствующие образам, которые уже есть в его сознании и которые не противоречат его интересам и установкам, что согласуется с идеей о благополучии как взаимодополняемости объективного и субъективного. При этом в процессах конструировании концепта «политическое благополучие» как образа для других особое значение приобретают процессы социальной стереотипизации. Люди воспринимают окружающий мир в форме стереотипов, а сами стереотипы формируются не индивидуально, а извлекаются извне. Основным источником служат СМИ. Липпман видел причину этого в том, что любая газета в руках индивида - это результат целой серии фильтров, т. к. перед попаданием к читателю она претерпевает упрощения и изменения [13].

Такая деятельность в своей основе имеет ряд механизмов, в рамках которых особую роль приобретают средства информирования, которые производят отбор и «сервировку» информации, «оптимизируя» ее получение потребителем. В результате деятельности масс-медиа формируются так называемые информационные фильтры, и в ходе переформулировки сообщений создается сконструированная реальность, опирающаяся на устоявшиеся социальные стереотипы. Этот процесс конструирования образа политической реальности ориентирован на субъектные информационные фильтры, основой которых являются собственные мотивы, цели и возможности реализации.

Информирование осуществляется с помощью специальных методов. Представляется, что в настоящее время в деятельности СМИ сформирован своеобразный «методологический стереотип» оказания воздействия на общественное мнение. Например, в качестве основных его компонентов можно выделить фабрикацию и избирательность подачи фактов. В этой связи масс-медиа широко используют принцип демократии шума - потопление сообщения, которого невозможно избежать, в хаотическом потоке бессмысленной, пустопорожней информации. Реклама разбивает информацию, делая ее лишь набором ничего не значащих кадров, а современные средства обработки информации могут сделать полностью невозможной оценку поступающей информации. Укрепляет эффект влияния на общественное сознание реализация таких методов, как манипулятивная семантика, которая предполагает изменение смысла слов и понятий, упрощение и стереотипизация понятий, фрагментирование и дробление информации, а также эффект сенсации, позволяющий дозировать и акцентировать информацию в нужном, заданном контексте. Массовое политическое манипулирование активно формирует концепт «политическое благополучие». Это проявляется двояко. Во-первых, через те действия, исполнители которых ориентированы на цели, в корне противопо- 
ложные официально декларируемым (это так называемое институциональнофинансовое манипулирование, реализуемое, к примеру, в ходе выборов). Во-вторых, посредством скрытых форм управления сознанием и поведением (при этом арсенал средств огромен - от использования мифа до специальных технологий создания иллюзорного сознания (полуправда, спираль умолчания, искажающий реальность монтаж кадров)). При этом процесс политического манипулирования ориентирован на потенциал устойчивости стереотипов. Например, в войне имиджей политиков «сильные» имиджевые характеристики вытесняют более «слабые», если конструирование имиджа опирается на существующие в человеке стереотипные представления о ситуации. Имидж способен оказаться с легкостью воспринятым. С помощью имиджевых характеристик Р. Рейган в ходе избирательной кампании против Дж. Картера моделировался СМИ как сильный лидер. Имидж У. Черчилля с сигарой поддерживался, «работал» и тогда, когда он уже не курил. И когда У. Черчилля фотографировали или он появлялся на публике, он доставал потухшую сигару, что говорит о силе стереотипов в избранной СМИ имиджевой характеристики. Как отмечает Дуглас, описывая социальные стереотипы в отношении политических партий, партийная идентичность всегда была основана на их ориентации на группы в обществе. Группа теории партий считает, что граждане оценивают политические партии в соответствии с их социальными стереотипами [16]. В этой ситуации наибольшее значение приобретает создаваемое впечатление, так называемые «разогретые» образы массового сознания. Сегодня, например, обсуждение в социальных сетях влияет на имиджевую оценку кандидата, что приводит к увеличению поддержки кандидата [17].

Однако, нужно заместить, что стереотипы лишь отчасти рождаются СМИ, они скорее ими тиражируются.

Итак, как было определено выше, идея формирования общественного мнения лежит в основе концепта «политическое благополучие» - «образ для других», поскольку общественное - это то, что вызывает интерес социума, то что несет социуму благо. В процессе коммуникативного конструирования такого концепта активно задействован инструментарий стереотипизации. По сути, это необходимый человеку способ мышления, создания смысловых «пучков». С нашей точки зрения именно социальные стереотипы становятся ключевыми инструментами в конструировании концепта «политическое благополучие» России в формате «образ для других». В.О. Рукавишников пишет: «восприятие России элитой и массами на Западе было и остается основанным на мифах и стереотипах, усвоенных в период ранней социализации, и на недоверии к русским и их лидерам» [18]. В известной работе ученого, политического активиста, профессора Университета «Джихад Против МакМира» (1995) Бенджамина Барбера присутствует мнение о том, волна международного терроризма во многом вызвана стереотипами. Некоторые предрассудки имеют общие межкультурные модели, а другие более изменчивы и специфичны для культуры [19]. Современные исследования, посвященные психологической реакции граждан на терроризм, показывают, что нападения, совершаемые лицами, принадлежащими к мусульманским меньшинствам, повышают негативное отношение к иммигрантам в целом. Авторы, изучая настроение жителей после террористического акта в Манчестере (22 мая 2017 года) утверждают, что эта эмпирическая закономерность может быть объяснена стереотипами, которые производят немедленную эмоциональную реакцию среди людей. Ссылаясь на теорию стереотипов авторы статьи показывают, что эффект действительно сильный и значительный в первые три дня после нападений, однако через четыре-семь дней эффект исчезает. Авторами сделан вывод, что воздействие терроризма на общественное мнение согласуется со стерео- 
типным эффектом, и поэтому, хотя оно и сразу же сильное, оно длится короткое времени [20].

Парадоксальность ситуации в том, что концепт «политическое благополучие», конструируемое в формате «образ для себя» в представлениях наших граждан тоже строится на стереотипах формата «образ для других». Поэтому зачастую представляется проблематичным отделить одну стратегию от другой. Социальные стереотипы есть неотъемлемые компоненты как массового, так и индивидуального сознания. Об этом писал У. Липпман, утверждая, что стереотипы в политике есть не сфера политики и идеологии, а сфера социальной психологии. П.С. Гуревич в своей работе «Стереотипы в политике» [21] ссылается на выводы Ф. Ницше, В. Парето, Ф. Бэкона. Он подчеркивает, что шаблоны сознания во многом определяют поведение человека, особенно если он высказывает свое мнение по тем вопросам, о которых он имеет весьма поверхностное представление, не располагая ни знанием, ни полной информацией [22]. Проблема в том, что человек современного «текучего» мира зачастую и не стремится быть осведомленным. Специфика современной социокультурной ситуации определяется тем, что коммуникации, объединяя различные уровни культуры, пронизывают, распределяют и транслируют информацию, которая оказывает влияние на процессы стереотипизации. Например, как пишет Сьюзан Фиске, многие граждане выражают политическое негодование по отношению к элитам. В этом контексте присутствует негативная реакция на общие вызовы системы. Впечатления, стереотипы, убеждения помогают объяснить популярные стереотипы, присутствующие в политическом дискурсе [23].

Проявлением экспансии плотной сети коммуникаций является тиражирование стереотипов заблуждений (в том числе, посредством СМИ), поскольку цензура здравого смысла отсутствует и, как следствие, растут обскурантизм и невежество населения (стоит отметить, что в то же время СМИ выполняют и образовательную функцию, однако поскольку человек не способен «фильтровать» огромные потоки информации самостоятельно, первое преобладает над вторым). С другой стороны, человек вообще перестает доверять любой информации, поскольку СМИ многократно попадались на лжи. Это ведет к затруднению идентификации: невозможно быть идентифицированным с тем, во что нет веры. При этом открываются возможности для целенаправленного манипулирования этими информационными потоками. Сущность таких процессов видится исследователями, то в радужных тонах, то как деградация самой культуры, проявляющаяся в усилении разобщенности индивидов, фрагментарности, иллюзорности самой реальности. Поэтому современные исследования, направленные на исследование коммуникативных практик, необходимы для преодоления разрушительных последствий манипуляций.

Исследование выполнено при финансовой поддержке РФФИ и ЭИСИ в рамках научного проекта № 20-011-31100.

\section{СПИСОК ЛИТЕРАТУРЫ}

1. Новая философская энциклопедия «КОНЦЕПТ». URL: https:/gufo.me/dict/philosophy_encyclopedia/ $\% \mathrm{D} 0 \% 9 \mathrm{~A} \% \mathrm{D} 0 \% 9 \mathrm{E} \% \mathrm{D} 0 \% 9 \mathrm{D} \% \mathrm{D} 0 \% \mathrm{~A} 6 \% \mathrm{D} 0 \% 95 \% \mathrm{D} 0 \% 9 \mathrm{~F} \% \mathrm{D} 0 \% \mathrm{~A} 2$ (дата обращения 11.01.2021).

2. Неретина С.С., Огурцов А.П. Концепты политической культуры. - М.: ИФРАН, 2011. - 276 с.

3. Smith D.M. The geography of social well-being in the United States: an introduction to territorial social indicators. - New York: McGraw-Hill, 1973. - 144 p.

4. Haas B.K. Clarification and integration of similar quality of life concepts // Journal of Nursing Scholarship. - 1999. - V. 31 (3). - P. 215-220.

5. Карамзин Н. Разговор о счастии. О счастливейшем времени жизни: сочинения в 2 т. Т. 2. - Л.: Художественная литература, 1984. - С. 190-206.

6. Аристотель. Никомахова этика: сочинения в 4 т. Т. 4. - М.: Мысль, 1983. - С. 53-295. 
7. Платон. Государство: собрание сочинений в 4 т. Т. 3. - М.: Мысль, 1971. - С. 89-455.

8. Виндельбанд В. Избранное: дух и история. - М.: Юрист, 1995. - 687 с.

9. Гегель Г. Работы разных лет. В 2 т. Т. 2. - М.: Мысль, 1971. - 630 с.

10. Parfit D. Reasons and persons. - New York: Oxford University Press, 1984. - 541 p.

11. Griffin J. Well-being: its meaning, measurement and moral importance. - Oxford: Clarendon Press, 1986. $424 \mathrm{p}$.

12. Лукьянова Н.А. Символический капитал власти в технологиях конструирования национальной идентичности // Ученые записки Забайкальского государственного университета. - 2013. - № 4 (51). C. $122-127$.

13. Липпман У. Общественное мнение. - М.: Институт Фонда «Общественное мнение», 2004. - 384 с.

14. Ноэль-Нойман Э. Общественное мнение. Открытие спирали молчания. - М.: Прогресс-Академия: Весь Мир, 1996. - 352 с.

15. Стереотип социальный // Философский энциклопедический словарь. URL: https://terme.ru/termin/socialnyi-stereotip.html (дата обращения 11.01.2021).

16. Douglas J.A. The group theory of parties: identity politics, party stereotypes, and polarization in the $21 \mathrm{st}$ century // Forum-a journal of applied research in contemporary politics. - 2018. - V. 16-1. - P. 3-22.

17. Freddie J., Calvin R. 'I just don't think she has a presidential look:' the influence of sexism on candidate image // Information communication \& society. - 2020 - V. 23 (9). - P. 1353-1367.

18. Рукавишников В.О. Холодная война, холодный мир: общественное мнение в США и Европе о СССР/России, внешней политике и безопасности Запада. - М.: Акад. Проект, 2005. - 862 с.

19. Fiske S. Prejudices in cultural contexts: shared stereotypes (gender, age) versus variable stereotypes (race, ethnicity, religion) // Perspect Psychol Sci. - 2017. - V. 12 (5). - P. 791-799.

20. Mancosu M., Ferrin M., Cappiali T. Terrorist attacks, stereotyping, and attitudes toward immigrants: the case of the manchester bombing // Social science quarterly. - 2018. - V. 102. - Iss. 1. URL: https://onlinelibrary.wiley.com/doi/10.1111/ssqu.12907 (дата обращения 11.01.2021).

21. Гуревич П.С. Стереотипы в политике. URL: https://psyfactor.org/lib/stereotype14.htm\#_ftn9 (дата обращения 12.01.2021).

22. Шихирев П.Н. Исследования стереотипа в американской социальной науке // Вопросы философии. 1971. - № 5. - C. 168-175.

23. Fiske S. Political cognition helps explain social class divides: two dimensions of candidate impressions, group stereotypes, and meritocracy beliefs // Cognition. - 2019. - V. 18. - P. 108-115.

Поступила 14.01.2021 г. 
UDC 316.334.3:32:316.653-049.2

\title{
COMMUNICATIVE STRATEGIES FOR CONSTRUCTING «POLITICAL WELL-BEING» CONCEPT
}

\author{
Natalia A. Lukyanova1,2, \\ lukianova@tpu.ru \\ Pavel N. Rvalov ${ }^{1}$, \\ rvalov@tpu.ru \\ 1 National Research Tomsk Polytechnic University, \\ 30, Lenin avenue, Tomsk, 634050, Russia \\ 2 Yaroslav-the-Wise Novgorod State University, \\ 41, B. St. Petersburgskaya street, Veliky Novgorod, 173003, Russia
}

Natalia A. Lukyanova, Dr. Sc., Head of Department for Social Sciences and Humanities, National Research Tomsk Polytechnic University.

Pavel N. Rvalov, Cand. Sc., Head of the Department of Youth and Social Policy, National Research Tomsk Polytechnic University.

Relevance. The establishment of the patterns of constructing "political well-being» concept in the dense network of communications of modern culture is a significant scientific problem and it allows forming a new, interdisciplinary subject field in modern philosophical and cultural studies. The aim of the research is to identify communicative strategies for constructing «political well-being» concept due to the patterns of stereotyping in socio-cultural communications and the peculiarities of the ability to cognize the world through its construction. Methods. The authors use a number of methods that allow philosophical and sociopsychological analysis of the essence and interdependence of «well-being» and «politics» concepts. The role of stereotypes in constructing "political well-being» concept is considered on the basis of the theory of public opinion by W. Lippmann. Results. Political well-being is considered as the experience of a set of objective circumstances determined by the system of power relations and institutions of power in conjunction with the subjective state. The construction of «political well-being» concept is directly related to communication processes as a way of speaking about the world of politics, characteristic of various social groups and entailing various social actions. In the process of construction, two communication strategies become the main ones: within the framework of the first communication strategy, an «image for oneself» is formed - the understanding of political well-being as one's own good, which consists of a complex of personal traditional goods. The second communication strategy is an «image for others» - political, cultural and other realities, customs, national myths, symbols, beliefs, stereotypes. This strategy is based on the mechanisms of public opinion formation and the importance of social stereotyping is emphasized. Conclusion. The "political well-being» concept is constructed through two communication strategies. The paradoxical feature of the situation is that the «political well-being» concept in the «image for oneself» format in the perceptions of citizens is based on the stereotypes of the «image for others» format.

Key words: Communication, political well-being, construction, concept, stereotype, politics, manipulation, theory of public opinion.

The research was financially supported by the RFBR and EISI within the scientific project no. 20-011-31100.

\section{REFERENCES}

1. Novaya filosofskaya entsiklopediya «KONTSEPT» [New philosophical encyclopedia «CONCEPT». Available at: https://gufo.me/dict/philosophy_encyclopedia/\%D0\%9A\%D0\%9E\%D0\%9D\%D0\%A6\%D0\%95\% D0\%9F\%D0\%A2 (accessed 11 January 2021). 
2. Neretina S.S., Ogurtsov A.P. Kontsepty politicheskoy kultury [Concepts of political culture]. Moscow, IFRAN Publ., 2011. 276 p.

3. Smith D.M. The geography of social well-being in the United States: an introduction to territorial social indicators. New York, McGraw-Hill, 1973. 144 p.

4. Haas B.K. Clarification and integration of similar quality of life concepts. Journal of Nursing Scholarship, 1999, no. 31 (3), pp. 215-220.

5. Karamzin N. Razgovor o shchastii. O shchastliveyshem vremeni zhizni [Conversation about happiness. About the happiest time of life]. Sochineniya v 2 t. T. 2 [Works in 2 volumes. Vol. 2]. Leningrad, Khudozhestvennaya literatura Publ., 1984. pp. 190-206.

6. Aristotel. Nikomakhova etika [Nicomachean Ethics]. Sochineniya v 4 t. T. 4 [Works: In 4 volumes. Vol. 4]. Moscow, Mysl Publ., 1983. pp. 53-295.

7. Platon. Gosudarstvo [State]. Sobranie sochineniy v 4 t. T. 3 [Collected works in 4 volumes. Vol. 3]. Moscow, Mysl Publ., 1971. pp. 89-455.

8. Vindelband V. Izbrannoe: dukh i istoriya [Selected: spirit and history]. Moscow, Yurist Publ., 1995. 687 p.

9. Gegel G. Raboty raznyh let. V 2 t. T. 2. [Works of different years. In two volumes. Vol. 2]. Moscow, Mys1 Publ., 1971. 630 p.

10. Parfit D. Reasons and persons. New York, Oxford University Press, 1984. 541 p.

11. Griffin J. Well-being: its meaning, measurement and moral importance. Oxford, Clarendon Press, 1986. $424 \mathrm{p}$.

12. Lukyanova N.A. Simvolicheskiy kapital vlasti $\mathrm{v}$ tekhnologiyakh konstruirovaniya natsionalnoy identichnosti [The symbolic capital of power in technologies for constructing national identity]. Uchenye zapiski Zabaykalskogo gosudarstvennogo universiteta, 2013, no. 4 (51), pp. 122-127.

13. Lippman U. Obshchestvennoe mnenie [Public opinion]. Moscow, Institut Fonda «Obshchestvennoe mnenie», 2004. 384 p.

14. Noel-Noyman E. Obshchestvennoe mnenie. Otkrytie spirali molchaniya [Public opinion. Opening a spiral of silence]. Moscow, Progress-Akademiya Publ., Ves Mir Publ., 1996. 352 p.

15. Stereotip sotsialny [Social stereotype]. Filosofskiy entsiklopedicheskiy slovar [Philosophical Encyclopedic Dictionary]. Available at: https://terme.ru/termin/socialnyi-stereotip.html (accessed 11 January 2021).

16. Douglas J.A. The group theory of parties: identity politics, party stereotypes, and polarization in the $21^{\text {st }}$ century. Forum-a journal of applied research in contemporary politics, 2018, vol. 16-1, pp. 3-22.

17. Freddie J., Calvin R.'I just don't think she has a presidential look:' the influence of sexism on candidate image. Information communication \& society, 2020, vol. 23 (9), pp. 1367-1353

18. Rukavishnikov V.O. Kholodnaya voyna, kholodny mir: obshchestvennoe mnenie v SShA $i$ Evrope o SSSR/Rossii, vneshney politike $i$ bezopasnosti Zapada [Cold War, Cold World: public opinion in the USA and Europe about the USSR/Russia, western foreign policy and security]. Moscow, Akad. Proekt Publ., 2005. $862 \mathrm{p}$.

19. Fiske S. Prejudices in cultural contexts: shared stereotypes (gender, age) versus variable stereotypes (race, ethnicity, religion). Perspect Psychol Sci., 2017, no. 12 (5), pp. 791-799.

20. Mancosu M., Ferrin M., Cappiali T. Terrorist attacks, stereotyping, and attitudes toward immigrants: the case of the manchester bombing. Social science quarterly, 2018, vol. 102, Iss. 1. Available at: https://onlinelibrary.wiley.com/doi/10.1111/ssqu.12907 (accessed 11 January 2021).

21. Gurevich P.S. Stereotipy $v$ politike [Stereotypes in politics]. Available at: https://psyfactor.org/lib/ stereotype14.htm\#_ftn9 (accessed 12 January 2021).

22. Shihirev P.N. Issledovaniya stereotipa v amerikanskoy sotsialnoy nauke [Research on stereotypes in American social science]. Voprosy filosofii, 1971, no. 5, pp. 168-175.

23. Fiske S. Political cognition helps explain social class divides: two dimensions of candidate impressions, group stereotypes, and meritocracy beliefs. Cognition, 2019, vol. 18, pp. 108-115.

Received: 14 January 2021. 